\title{
Contribuições do sistema didático Galperin-Talízina para a organização do ensino de geometria
}

\author{
Contributions of the Galperin-Talízina didactic system for the \\ organization of geometry education
}

\author{
Adriana Rodrigues ${ }^{1}$ \\ Patrícia Lopes Jorge Franco ${ }^{2}$ \\ José Renato Buêncio ${ }^{3}$
}

\begin{abstract}
RESUMO
Os conteúdos geométricos encontram-se marginalmente nos currículos desde a Educação Básica e o seu ensino aligeirado pouco tem a contribuir para a qualidade da aprendizagem e da formação do pensamento geométrico dos estudantes. $\mathrm{O}$ presente texto apresenta possibilidades de organização do ensino de conceitos geométricos, a partir dos pressupostos da Teoria de Assimilação por Etapas das Ações Mentais de Galperin e da Teoria da atividade em Talízina e Volodarskaya. Caracteriza-se como estudo teórico-bibliográfico sobre as bases filosóficas e epistemológicas do materialismo histórico-dialético que sustentam essa organização intencional do ensino na área de matemática. Evidencia-se que, durante o processo de aprender - assimilar um conceito a nível da consciência e da generalização -, as ações atuam de acordo com uma base orientadora e são modificadas desde a sua forma material até a ação mental, agora, integrada ao pensamento. No campo da Didática, esse resultado e seus potenciais desdobramentos são muito importantes ao comprovarem que é possível organizar as ações de assimilação de conceitos geométricos por meio de atividades de aprendizagem planejadas.
\end{abstract}

Palavras-chave: Organização do ensino. Sistema didático Galperin-Talízina. Conceitos geométricos.

\begin{abstract}
The geometric content has been marginally in the curricula since Basic Education and its light education has little to contribute to the quality of learning and the formation of students' geometric thinking. The present text presents possibilities of organization of the teaching of geometric concepts, based on the assumptions of the Theory of Staged Assimilation of Galperin Mental Actions and the Theory of activity in Talizin and Valadarskaya. It is characterized as a theoretical-bibliographic study on the philosophical and epistemological bases of historical-dialectical materialism that support this intentional organization of teaching in the area of mathematics. It is evident that during the process of learning - assimilating a concept at the level of consciousness and generalization - actions act according to a guiding principle and are modified from their material form to mental action, now integrated with thought. In the field of Didactics, this result and its potential developments are very important in proving that it is possible to organize the actions of assimilation of geometrical concepts through planned learning activities.
\end{abstract}

Keywords: Organization of teaching. GalperinTalízina didactic system. Geometrical concepts.

\footnotetext{
${ }^{1}$ Doutora em Educação pela Universidade Federal de Uberlândia-UFU/FACED. Professora no Programa de Pós-graduação em Educação da UNIUBE/MG. Membro do GEPIDE - Grupo de Estudos e Pesquisas em Instrução, Desenvolvimento e Educação. E-mail: adriana.rodrigues@uniube.br.

2 Doutora em Educação pela Universidade Federal de Uberlândia UFU/FACED. Membro efetivo do GEPEDI- Grupo de Estudos e Pesquisas em Didática Desenvolvimental e Profissionalização Docente (UFU/PPGED). E-mail: patricia.jfranco11@gmail.com.

${ }^{3}$ Professor de Matemática na UNIUBE/MG, Brasil. Mestrando do Programa de Pós-Graduação em Educação da UNIUBE/MG. E-mail: jose.buencio@uniube.br. 


\section{Introdução}

É inquestionável a importância da Geometria no desenvolvimento e avanço das civilizações humanas e, por séculos, o seu ensino foi tratado como primordial para o desenvolvimento da intelectualidade e raciocínio dos homens. Discuti-lo, na atualidade, configura-se em um desafio e, ao mesmo tempo, em uma necessidade teórico-prática da docência em Matemática, haja vista que, contraditoriamente a essa importância, tem-se um movimento histórico de secundarização e descaso dessa área do saber matemático.

Os conteúdos geométricos priorizados na educação escolar e a forma como o seu ensino tem sido organizado têm raízes históricas na dualidade de concepções que a tem acompanhado. A primeira concepção, de viés utilitarista, remonta à Geometria Egípcia, detém-se às formas e aos espaços geométricos, com centralidade no pensamento intuitivo e estreita vinculação às questões práticas do cotidiano, exemplificada nas grandes construções, nas marcações e divisões de porções de terras agricultáveis com cálculos de áreas, de perímetros etc. A segunda concepção, com base na Geometria Grega, possui um forte apelo e confiança na razão em contraposição à intuição, por isso de cunho mais formal e abstrato, primando pelas demonstrações, com a exigência de elaboração teórica e de dedução na constituição do pensamento geométrico. Esta concepção, com grande influência no seu ensino atual, prioriza o tratamento algébrico dos elementos geométricos desvinculando-se, muitas vezes, de seus aspectos espaciais com sérias consequências para a formação do aluno.

Nas décadas de 1950 e 1960, assiste-se, no Brasil, a uma reformulação no modo de conceber e estruturar o ensino de Matemática articulado às orientações internacionais gestadas no Movimento da Matemática Moderna (MMM), cujos norteamentos centravam-se na necessidade de aproximação da Matemática escolar da Matemática científica. A esse respeito Pavanello (1989) ressalta que:

[...] a ideia central da Matemática Moderna consistia em trabalhar a matemática do ponto de vista de estruturas algébricas com a utilização da linguagem simbólica da teoria dos conjuntos. Sob 
esta orientação, não só se enfatizava o ensino da álgebra, como se inviabilizava o da Geometria da forma como este era feito tradicionalmente. (PAVANELLO, 1989, p.103).

Esse movimento de algebrizar a Geometria, utilizando linguagens simbólica e lógica, fez com que a mesma fosse tratada como "uma parte da Álgebra”, tornando-se um conteúdo de difícil compreensão, preocupando-se com o uso das formulações com consequente prejuízo para o enfoque dado à construção da abstração e da generalização de conceitos geométricos, visto que, ao se algebrizar, foca-se em representações formais sem se preocupar, à priori, com a visão espacial que ela propõe como conhecimento de espaço e forma.

Assiste-se a mudanças expressivas no cenário educacional, variadas e sucessivas reformas governamentais, as quais contribuíram, em seu conjunto, para que a Geometria fosse tratada de forma secundária e situada de forma marginal nos programas escolares brasileiros. Como consequências imediatas, têm-se o descaso com a formação do professor para ensiná-la, as reformulações dos currículos da Educação Básica com notável inserção de conteúdos relacionados à Álgebra, como nos materiais e livros didáticos, nos quais os conteúdos de Geometria ficavam ao seu final e, principalmente, a dissociação da unidade teoria-prática, sujeito-objeto na formação do pensamento geométrico.

Essa realidade foi constatada em pesquisa sobre o lugar dos conceitos geométricos nas tarefas escolares, na qual Locatelli (2015, p.99), afirma que "Em todas as turmas analisadas, os conteúdos geométricos foram explorados em períodos isolados [...] confirmando assim, que os conteúdos de geometria ficam para segundo plano.

Seu retorno à pauta educativa das políticas públicas está expresso nos Parâmetros Curriculares Nacionais (PCNs) e prossegue na nova Base Nacional Comum Curricular (BNCC), na qual tem-se indicações de sua importância para outras áreas do conhecimento. A BNCC, mesmo que represente um certo avanço para o destaque dado à Geometria, não rompe com a tendência simplificadora e superficial de situá-la e traz, de forma muito incipiente e vaga, a formação do pensamento geométrico, ao não apresentar nem a fundamentação teórico-prática do ensino-aprendizagem ou mesmo uma orientação de como ensiná-la e como 
formar esse pensamento, limitando-se a fazer afirmações, tais como:

A Geometria envolve o estudo de um amplo conjunto de conceitos e procedimentos necessários para resolver problemas do mundo físico e de diferentes áreas do conhecimento. Assim, nessa unidade temática, o estudo da posição e deslocamentos no espaço e o das formas e relações entre elementos de figuras planas e espaciais pode desenvolver o pensamento geométrico dos alunos. Esse pensamento é necessário para investigar propriedades, fazer conjecturas e produzir argumentos geométricos convincentes. É importante, também, considerar o aspecto funcional que deve estar presente no estudo da Geometria: as transformações geométricas, sobretudo as simetrias. As ideias matemáticas fundamentais associadas a essa temática são, principalmente, construção, representação e interdependência. (BRASIL, 2017, p.229).

Analisando este contexto histórico contemporâneo do ensino da Geometria desde a Geometria não-euclidiana, passando pelo Movimento da Matemática Moderna - MMM, e com a análise da construção da Base Nacional Comum Curricular - BNCC, utilizando como parâmetros os resultados de avaliações externas (ENEM, PROEB, PROALFA, PROVA BRASIL), verificamos que o ensino da Geometria é na realidade educacional brasileira "abandonado", desde a Educação Infantil e Ensino Fundamental. São fatores que evidenciam o afastamento dos alunos do saber matemático, como evidenciado nos estudos de Franco (2015); Longarezi e Franco (2015) e Franco; Longarezi e Marco (2016, 2017).

Em contraposição a essa situação, é preciso resgatar a Geometria enquanto área do saber fundamental para a formação integral dos alunos, destacar a valorização do conhecimento de conteúdos geométricos, a necessidade de melhoria da formação de professores e de pesquisas sobre o ensino-aprendizagem a partir de indagações sobre o que ensinar e como fazê-lo com qualidade.

Diante dos problemas apresentados, de secundarização histórica da Geometria na estrutura curricular, tendo-se, como reflexo, a formação aligeirada do professor que atua no ensino de Matemática, as contribuições de Talízina (2000, 2009) vêm ao encontro de oportunizar possibilidades teórico-metodológicas para o ensino de conteúdos de Geometria com vistas ao desenvolvimento das ações mentais dos alunos. Juntamente com os princípios formulados por 
Galperin $^{4}$ (2001, 2017) e as especificidades de algumas atividades de Volodarskaya (2001). Defende-se, no contexto desse texto, a organização intencional do ensino da Geometria à luz das proposições do sistema didático Galperin-Talízina 5 .

Argumenta-se que o ensino organizado sob as bases da Teoria da Formação por Etapas das Ações Mentais e dos Conceitos, por meio da assimilação dos conceitos científicos materializados e transformados nos conteúdos escolares, pode contribuir para a formação das funções psicológicas superiores como: abstração, raciocínio lógico- dedutivo, generalizações, orientação e criatividade espaciais com interface com a realidade virtual e o raciocínio visual.

$\mathrm{Na}$ direção do enfrentamento das necessidades e desafios postos, abordamse as bases filosóficas e epistemológicas que sustentam esse olhar para as questões que emergem na contemporaneidade em relação ao ensino de Geometria, juntamente com os princípios formulados por Galperin (2001, 2017). Em seguida, apresentam-se as especificidades de algumas atividades de ensino que abordam conteúdos geométricos como retas, ângulos, bissetriz, circunferência, elipse etc. expostos em Talízina (2000) e Volodarskaya (2001), com a sua reprodução, representação dos elementos por meio gráfico e análise.

\section{As bases fundantes do sistema didático}

\section{Galperin-Talízina: aproximações necessárias}

Compreende-se que o homem constitui suas formas de ação e sua consciência nas relações sociais que são estabelecidas com os demais. Marx e Engels (2008, p. 34) afirmam que "a linguagem é a consciência real, prática, que existe para os outros homens e que, portanto, também existe para mim mesmo; e a linguagem nasce, tal como a consciência, do carecimento da necessidade de

\footnotetext{
${ }_{4}^{4}$ Piotr Yakovlevich Galperin foi professor da Universidade Estadual M. Lomonosov de Moscou e trabalhou na escola de Karkov, fundada pelo grupo de Vigotski, Leontiev e Luria e desenvolveu pesquisas experimentais em um longo período (30 anos) e deu continuidade aos estudos de Vigotski e Leontiev, este último sobre a Teoria da Atividade.

${ }^{5}$ Puentes (2017), em seus estudos sobre a Didática Desenvolvimental da Atividade, constatou que diferentes interpretações de alguns postulados de L. S. Vigotski, S. L. Rubinstein e A. N. Leontiev deram origem a sistemas didáticos distintos, embora tenham a mesma base teórica. São eles: o sistema zankoviano, o sistema Galperin-Talízina e o sistema Elkonin-Davidov.
} 
intercâmbio com outros homens", constituindo-se, portanto, em produto social. Nessa passagem encontra-se a tese fundamental da natureza social da consciência.

Leontiev $(1978,1983)$ explica que a natureza do homem é social e tudo que tem de humano nele provém de sua vida em sociedade, da cultura criada e objetivada pela humanidade. Compreende-se que o homem constitui suas formas de ação e sua consciência nas relações sociais que são estabelecidas com os demais. De forma análoga, o desenvolvimento e aprimoramento da linguagem são impulsionados por necessidades conscientes do homem.

Vygotski (1996) define o lugar das relações sociais que o indivíduo estabelece com o mundo exterior ao defender que o trânsito do desenvolvimento do pensamento é do social para o individual e não o contrário. O sujeito nesse processo interioriza determinadas formas de funcionamento que são dadas pela cultura e, ao apropriar-se delas, transforma-as em instrumentos de pensamento e ação. Essa mediação é necessária para que ocorra a internalização das formas culturais e históricas, em um movimento que vai do interpsíquico (âmbito do coletivo-social) para o intrapsíquico (no âmbito da pessoalidade - individual), ou seja, uma ocorre uma reconstrução interna dos processos externos culminando nos processos de apropriação e objetivação da natureza. Nesse processo de apropriação ocorre:

[...]a reelaboração e reconfiguração do patrimônio históricocultural (campo do significado) para que, ao apreendê-lo, possa dele fazer uso, dar-lhe sentido. Nisso reside o desenvolvimento ontogênico humano, um ser que se apropria, transforma e transmite a prática sócio-histórica da humanidade, podendo também transformar a si mesmo em uma relação de dupla constituição. (LONGAREZI e FRANCO, 2017, p. 267).

Acresce-se ao exposto, o fato das funções psicológicas superiores se desenvolverem mediante a apropriação da cultura e, uma das vias dessa apropriação, é pela aprendizagem escolar. Neste sentido, a compreensão da relação dialética entre a aprendizagem e o desenvolvimento torna-se, então, essencial para o estudo de qualquer área do conhecimento, da organização didática do trabalho pedagógico e da efetivação do processo de ensinoaprendizagem de conceitos. 
A esse respeito, destaca-se que Vigotski e Leontiev não pretenderam investigar ações didáticas para a aprendizagem dos conceitos, essa tarefa foi realizada por outros pesquisadores russos como Galperin, Talízina, Davidov, Elkonin, entre outros teóricos que formaram a segunda e terceira gerações continuadores dos estudos da Teoria Histórico Cultural e da Teoria da Atividade.

Galperin, em continuidade aos estudos científicos de Vigotski e Leontiev, realizou diversas pesquisas experimentais durante três décadas, as quais possibilitaram a criação da Teoria da Formação por Etapas das Ações Mentais e dos Conceitos. Galperin $(2001,2017)$ buscou respostas sobre como são assimiladas as experiências sociais externas pelos indivíduos, ou seja, como é realizado o trânsito da ação, que de início é objetiva, para a ação mental interpsíquico para o intrapsíquico, quais ações e como são processadas na internalização de conceitos na atividade do sujeito. Para tanto, foi preciso reduzir o objeto de estudo da atividade que, em Leontiev, era tomada em uma concepção muito ampla. Assim o fez, tomando em suas pesquisas, como unidade de análise, a ação, no caso da ação mental - entendida como habilidade de transformar mentalmente um objeto.

Como os conhecimentos, em sua maioria, formam-se no processo de aprendizagem escolar, mesmo sem intencionar construir uma teoria didática, Galperin (2001) direcionou suas pesquisas para a formação de conhecimentos escolares, pautando-se na formação das representações ou imagens mentais e dos conceitos. Essas investigações em torno da assimilação de diversos conceitos e em diferentes níveis de ensino apontaram que no processo de assimilação, as ações que eram externas, portanto materiais, são convertidas em ações internas ou mentais sendo que, neste processo, podem ser identificadas quatro etapas: formação da base orientadora da ação; etapa da ação materializada; etapa da ação na linguagem externa, etapa da ação na linguagem interna. Essas formações, embora sejam divididas por seu objetivo no ato de conhecer/aprender, não são isoladas, havendo uma necessária integração entre as mesmas. Isso fica evidente em suas palavras:

As etapas principais em que dividimos a formação do conceito não são "puras". Pelo contrário, em cada uma delas estão incluídos elementos de outras etapas. $\mathrm{Na}$ "ação materializada", os elementos 
da elaboração articulada; na "ação articulada", os elementos da representação das relações objetivas; na "ação mental", os elementos linguísticos externos. Devido a elaboração intensiva dos elementos de outras etapas, em cada nível se pode compensar a exclusão de qualquer outro nível, de tal forma que nenhum deles em forma isolada, é absolutamente necessário em um ou outro momento. (GALPERIN, 2001, p. 36, tradução nossa).

Destaca-se, nessa sistematização, um plano norteador, uma base orientadora das ações que serão realizadas, desde a sua forma material até o momento em que a ação seja integrada à psique, sustentando, portanto, que é possível planejar a formação de processos psíquicos, novos conhecimentos, habilidades, valores, atitudes e hábitos, em um sistema de etapas fundamentais com ações e operações. No campo da Didática esses resultados e seus desdobramentos são muito importantes ao concluir que é possível organizar as ações de assimilação de conceitos, por meio de atividades de aprendizagem planejadas. No que se refere à docência depreende-se que "organizar o ensino e orientar a formação das ações mentais para apropriação de conceitos, operou como objetivo-meio, efetivou-se como conteúdo e forma do processo formativo docente, com vistas ao alcance do seu objetivo-fim: desenvolvimento integral dos estudantes" (FRANCO; LONGAREZI e MARCO, 2016, p.138). Tal movimento se constitui em didático-formativo uma vez que se busca a efetivação desse tipo de assimilação de conceitos, no nível teórico por parte dos alunos.

Em consonância com a teoria de Galperin, a pesquisadora Talízina ${ }^{6}$ continuou suas pesquisas e fez vários experimentos didáticos nos quais utilizou as suas proposições na organização do ensino, notadamente de conteúdos de Física e Matemática. Os constructos de Galperin e seus seguidores como Talízina ampliaram a Teoria da Formação de Conceitos em Vigotski e da Teoria da Atividade em Leontiev, focalizando não apenas o seu processo de internalização ou a atividade principal norteadora deste e, sim quais as ações necessárias para que o conceito seja assimilado na forma de pensamento ou ação mental.

\footnotetext{
${ }^{6}$ Nina Fiódorovna Talízina, nasceu em 28 de dezembro de 1923 e estudou na escola de pósgraduação do Instituto de Ciências Pedagógicas da URSS. Em 1950, ela defendeu sua tese sobre "Peculiaridades do raciocínio geométrico na resolução problemas". É pesquisadora das aplicações práticas da teoria de Galperin.
} 


\section{Geometria}

Ensinar não se resume em transferir conhecimento, exige posições teóricas do professor na sua atuação, desde a organização intencional do ensino à avaliação e reestruturação do mesmo. Neste sentido, o ensino da Geometria deverá se pautar em assimilação de conceitos científicos desde os iniciais ou basilares, tais como: ponto, reta, ângulo, entre outros. Apresenta-se, a seguir, algumas atividades selecionadas em Talízina (2000) e Volodarskaya (2001) com as representações gráficas e análises.

3.1 conceito a outras situações

Primeira atividade: utilização do

Para Talízina (2000), a essência dos conceitos está na experiência social herdada de outras gerações e sua assimilação pelos alunos permite a possibilidade de conversão da experiência social em experiência individual e em imagem abstrata e generalizada do objeto. Os alunos reproduzem as definições dos conceitos, porém não os aplicam em situações da realidade ou na resolução de problemas, isto se deve ao formalismo do ensino. Isso pode ser verificado em:

Os alunos acabam de estudar o conceito de circunferência. Eles, fácil e corretamente, reproduzem a definição de circunferência, dizendo que é uma linha curva fechada e que todos os seus pontos se encontram à mesma distância de um ponto que se chama centro. Depois disto, aos alunos, se lhes propõem o desenho técnico de uma elipse, dentro da qual se coloca um ponto ("centro"). A esses alunos lhes é perguntado se podemos ou não chamar a esta linha curva, como circunferência. Uma parte significativa dos alunos afirma positivamente. À pergunta por que eles pensam assim, eles respondem: "Aqui também há um centro". (TALÍZINA, 2000, p.217).

Tal pensamento dos alunos faz com que se volte o olhar para as características e relações internas do conceito, a sua essência. O exemplo de Talízina (2000) demonstra que os alunos não compreenderam esse aspecto muito importante, e se detiveram somente no aspecto externo do mesmo. O fato de ter um centro não garante que seja uma circunferência. $O$ que evidencia a necessidade de que no planejamento do ensino o professor prepare ações a 
serem realizadas pelos alunos que os ajudem a compreender a essência do conceito que ensina, ou seja, suas características e relações internas.

Neste caso, os alunos não se apropriaram corretamente do conceito de circunferência, pois além do centro é necessário que os pontos que formam o lugar geométrico, denominado circunferência, estejam a uma mesma distância do centro (raio), ou seja, uma "Circunferência de centro O e raio r é o conjuntos de todos os pontos que distam $\mathrm{r}$ de $\mathrm{O}$. O raio da circunferência é qualquer segmento de reta com extremidades no centro e na circunferência.” Balestri (2016, p. 188), como se observa na (Figura 1). Esse tipo de análise e observação da característica interna do conceito de circunferência faz toda diferença em relação a uma elipse (Figura 2) a qual, de acordo com Balestri (2016, p. 204) "é o conjuntos de todos os pontos do plano cuja soma das distâncias a dois pontos fixos F1 e F2, denominados focos, é a constante $2 \mathrm{a}$, de modo que essa distância é maior que a distância entre os focos, dada por $2 \mathrm{c}$, isto é, $2 \mathrm{a}>2 \mathrm{c}$ ".

Figura 1 - Circunferência de Centro C e raio $\mathrm{r}$.

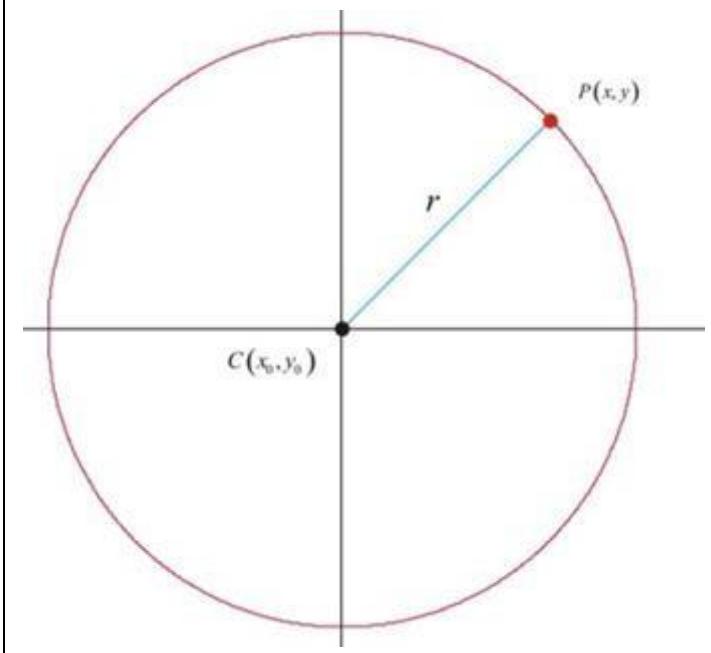

Fonte: Arquivo dos autores (2017).
Figura 2 - Elipse de centro $\mathrm{O}$ e focos $\mathrm{F} 1 \mathrm{e}$ F2.

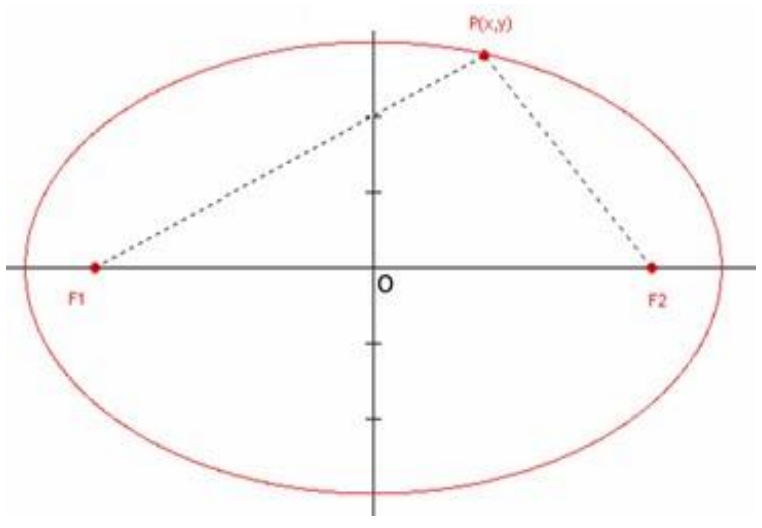

Fonte: Arquivo dos autores (2017).

Para entender um conceito geométrico, como por exemplo, o conceito de circunferência e utilizá-lo em outras situações particulares diversas, é preciso conhecer as relações essenciais entre os seus respectivos elementos (diâmetro e raio, centro e raio). 
Para Talízina (2000), têm-se dois tipos de ações, as gerais - aplicadas para os vários conteúdos e as ações, e as específicas - aplicadas para conteúdos particulares. São observadas algumas ações entre as generalizações, sendo as ações de reconhecimento, de classificação e de condução ao conceito, sendo que a unidade de análise deve considerar a necessidade de conservação das particularidades da atividade. A autora prossegue seu raciocínio argumentando que a generalização ocorre de acordo com as características incluídas na base orientadora da ação. Daí decorre que as características estão na totalidade dos objetos, podendo ser utilizadas na solução de problemas que exigem a sua aplicação, ou seja, encontram-se, na base da generalização, as características que não variam de todos os objetos da classe analisada. Portanto, se os conceitos não são assimilados em sua essência, os alunos não terão condições de estabelecer relações entre os objetos e suas particularidades dentro de uma mesma classe, o que impossibilitará a sua representação, verbalização e apropriação corretas.

As proposições de Talízina são importantes para o contexto escolar, na organização do ensino com a elaboração de atividades nas quais seja possível a criação da base de generalização e, a partir dela, a resolução de qualquer outro que exija as mesmas ações. É importante destacar que a organização didática do ensino para o desenvolvimento do aluno pauta-se na assimilação de conceitos, porém, de conceitos constitutivos de ações cuja base seja invariante.

Coadnuna-se com essas reflexões o exposto em Rodrigues (2015) ao ressaltar que a organização e a orientação do processo de formação das ações realizados pelo professor devem fomentar os interesses cognoscitivos dos estudantes, as quais exige interrelações com outros campos do conhecimento e o envolvimento de componentes pedagógicos, epistemológicos, cognitivos e didáticos, constituindo-se em grande desafio à prática pedagógica do professor.

\subsection{Segunda atividade: modelos representativos dos conceitos}

Os alunos estudaram os triângulos retângulos. Eles, de maneira muito segura, dizem que o triângulo se chama triângulo retângulo se este tem um ângulo reto. De imediato, é proposto a eles um triângulo retângulo com um ângulo reto em seu vértice superior. Os alunos medem o ângulo, confirmam que é reto, porém não estão de acordo em chamá-lo de triângulo retângulo. (TALÍZINA, 2000, 
p.217, tradução nossa).

$\mathrm{Na}$ segunda atividade, evidencia-se que o aluno não conseguiu sair da etapa materializada do conceito, de sua representação em um modelo. Isto remete ao fato de as definições geralmente serem pautadas em modelos únicos de representações, ou seja, na etapa materializada, o objeto é sempre apresentado seguindo o mesmo modelo, o que pode prejudicar o processo de assimilação do conceito em sua forma abstrata - descolada da materializada. Como pode ser observado nas (Figuras 3 e 4).

Figura 3 - Triângulo retângulo com ângulo reto posicionado na parte inferior.

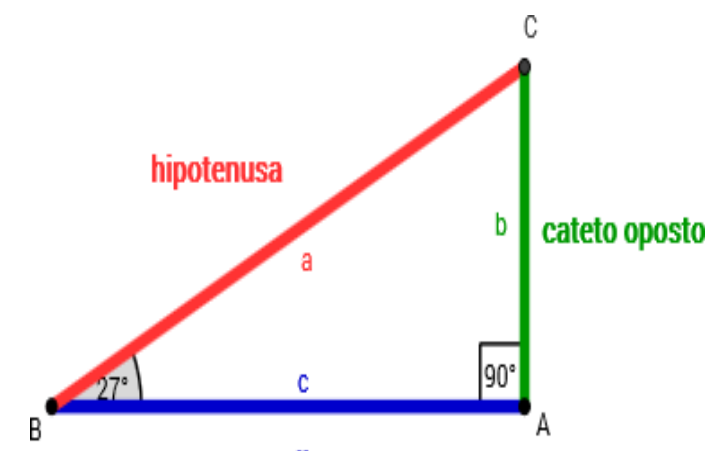

cateto adjacente

Fonte: Arquivo dos autores (2017).
Figura 4 - Triângulo retângulo com ângulo reto posicionado na parte superior

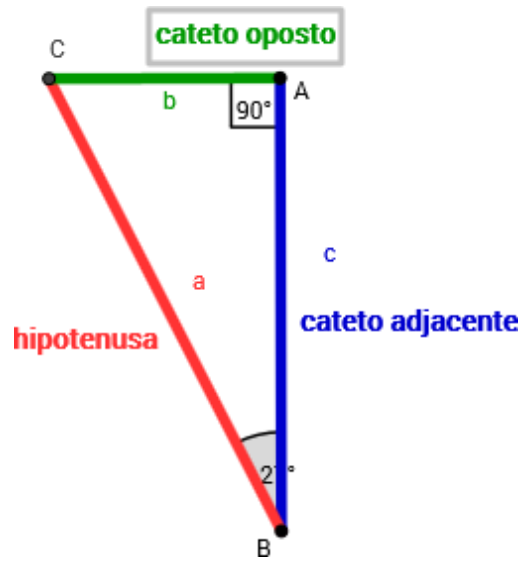

Fonte: Arquivo dos autores (2017).

Mudou-se o lugar do ângulo, da forma materializada de apresentação do modelo geométrico e o aluno não consegue estabelecer a relação principal do conceito, que é ter um ângulo de $90^{\circ}$, independente da rotação feita na figura. $\mathrm{O}$ problema é o uso de modelos, da mesma forma de apresentação nos livros didáticos, da indução da não-análise dos conceitos e do estabelecimento de relações com as demais possibilidades de representação de um triângulo retângulo. Isso tem forte vinculação com o uso de atividades propostas em livros didáticos sem o devido questionamento a elas e abertura à nova organização do ensino. 
Os alunos possuem uma apropriação incompleta do conceito de triângulo retângulo, considerando־o apenas aquele no qual o ângulo reto está localizado no vértice inferior. Destaca a importância de se trabalhar com um mesmo conceito em diferentes formas de apresentação materializada, mas mantendo-se a mesma relação fundamental - que constitui a sua essência mantendo-se a unidade conteúdo-forma. Em relação à etapa materializada, Talízina (2009) afirma a sua importância no êxito da assimilação dos conceitos.

\section{3}

Terceira atividade: condição necessária e

suficiente de um conceito

Nessa atividade toma-se como exemplo o conceito de ângulos adjacentes. Os alunos definem de forma correta ângulos adjacentes como sendo aqueles que têm vértice comum, um lado comum e os outros lados, consecutivos. Porém, diante da questão "Se dão dois ângulos com vértice comum. A soma destes ângulos é igual a $180^{\circ}$. São ou não estes ângulos adjacentes?” (TALÍZINA, 2000, p.217). A maioria dos alunos erra a resposta ao afirmar que os referidos ângulos são adjacentes, falta-lhes a informação sobre uma das condições necessárias para considerar um ângulo como adjacente: o lado comum. Neste caso, tem-se uma situação indeterminada, considerando que dois ângulos podem somar $180^{\circ} \mathrm{e}$ serem adjacentes ou serem opostos pelo vértice (Figuras 5 e 6). Se os alunos soubessem tais aspectos das características e relações internas dos conceitos, o correto seria eles responderem: "Não sabemos, os ângulos podem ser adjacentes ou não". 


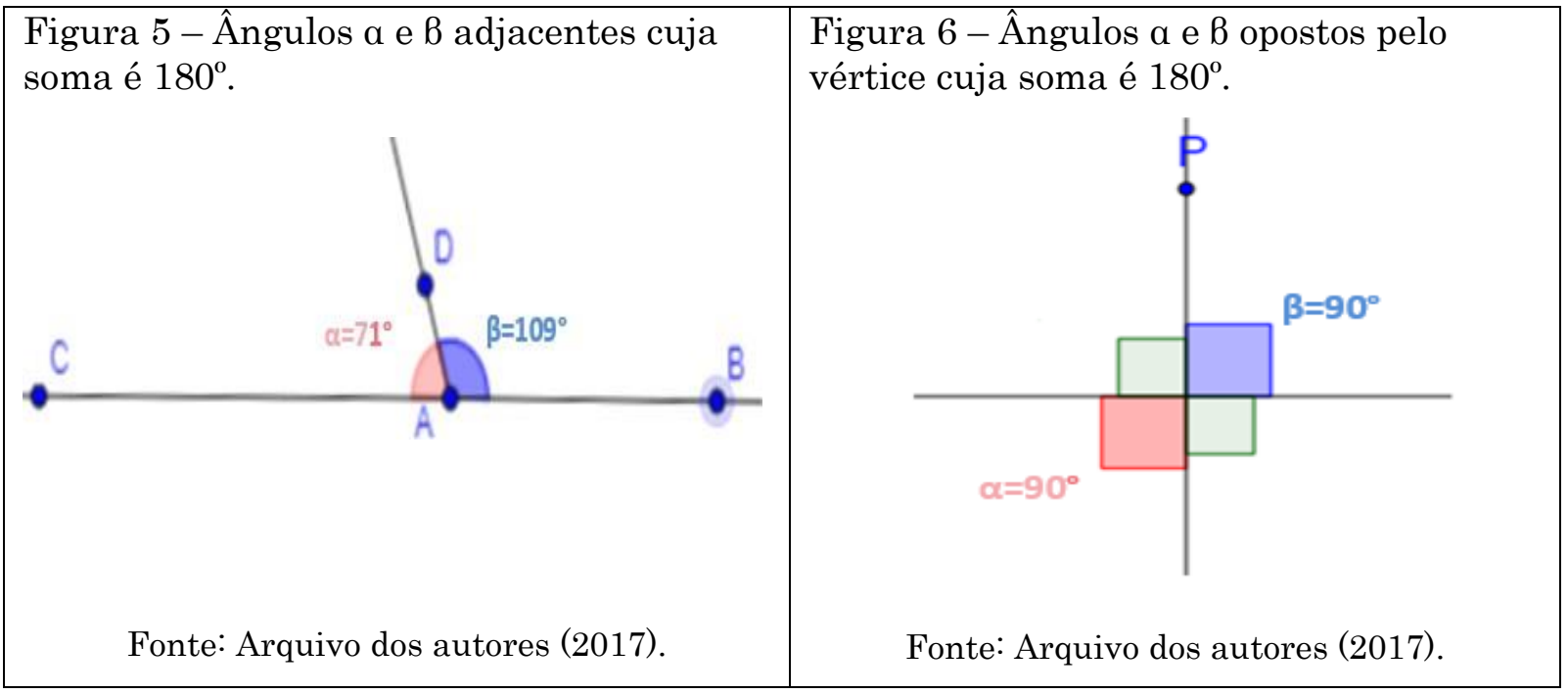

Com o referido exemplo, pode-se compreender a importância da consideração do conjunto de atributos necessários e suficientes que caracterizam um objeto em sua conceituação. Neste sentido, os alunos classificaram o ângulo como adjacente apoiando-se em aspectos isolados de suas características, no lugar de considerarem todo o sistema explicitado em sua definição, demonstrando dificuldades de operarem com condições lógicas e dialéticas de apropriação dos conceitos. A esse respeito, Talízina (2009) indica a necessidade de o professor trabalhar com comparações e classificações por meio de variados atributos ou características em níveis altos de dificuldades.

No segundo exemplo, retratado por Talízina (2000), é solicitado aos alunos que desenhem uma perpendicular e alguns deles desenham uma linha vertical. Ao analisar essa situação, constata-se a dificuldade dos alunos em trabalharem com conceitos relativos e absolutos considerando que eles "não consideram o caráter relativo dos conceitos e operam com eles como com os conceitos absolutos" (TALÍZINA, 2000, p.218, tradução nossa). Observa-se que o conceito absoluto de reta foi representado pela linha vertical. Entretanto não foi considerado o conceito relativo de reta perpendicular, que é uma reta que tem relação com o ângulo formado com outra reta.

Destaca-se, nessa atividade, a falta de verificação de uma condição necessária e suficiente para que uma reta seja perpendicular: uma reta só é perpendicular em relação a outro objeto geométrico (outra reta, um vetor, um 
plano). Neste caso, a autora destaca a importância do conhecimento das condições necessárias para a conceituação de um objeto. Coloca-se em questão o conhecimento dessas condições para realizar a atividade ou refutá-la. Constituindo, por sua vez, em um importante exercício de confirmação de condições necessárias e suficientes e, na falta de uma ou mais delas, argumentar na sua impossibilidade lógica de finalizá-la. É um trabalho com conceito que exige comparações e conhecimentos de lógica e de situações indeterminadas.

Com base no exposto pode-se afirmar que a organização do ensino de Geometria pautada em atividades de ensino que exploram as condições necessárias e suficientes e as suas relações internas lógicas promove o desenvolvimento das potencialidades para a argumentação lógica.

É importante observar a participação do aluno na atividade de desenhar, mesmo que tenha feito uma linha vertical sem vinculação com o conceito relativo de reta, pois, para Talízina (2009), ao executar uma ação, são colocadas em movimento três funções básicas, uma de orientação, uma de execução e, ainda outra de controle. A participação na atividade de desenhar possibilita identificar e corrigir a etapa da ação deficitária por meio da função controle ou correção.

Outro aspecto defendido em Talízina (2009) é a necessidade do aluno já ter assimilado as ações que são requeridas na apropriação de um conceito e suas consequências, com indicações didáticas de que "durante a formação da ação de condução do conceito, não se podem proporcionar aqueles exemplos, nos quais as características que se buscam, se dão de forma mediatizada” (p.228). Neste sentido, se o aluno está na fase de assimilação do conceito de reta perpendicular não é adequado trabalhar com exemplos que exploram esse conceito por meio de consequências de outras definições (Figura 7). Para essa exemplificação toma-se o seguinte questionamento "Como podemos estabelecer se são perpendiculares ou não a bissetriz do ângulo no vértice do triângulo equilátero, e a base deste triângulo?" (p.228).

Figura 7 - Construção de uma reta perpendicular pela mediatriz do segmento AB. 


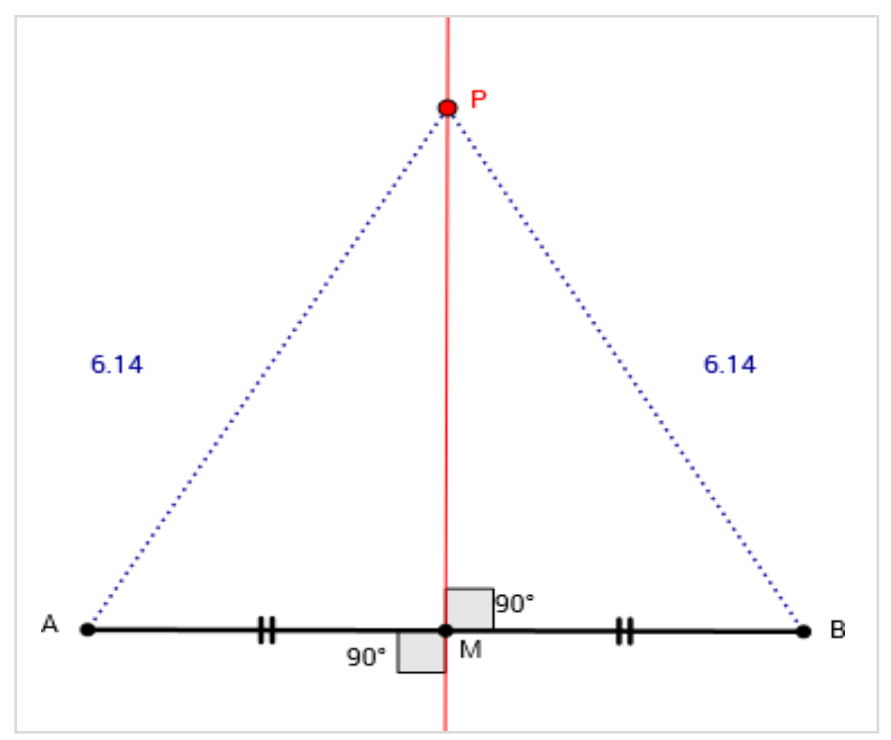

Fonte: Arquivo dos autores (2017).

Para que o aluno responda a esse questionamento é preciso que o professor tenha antecipado quais são as consequências quando se toma uma bissetriz (reta que divide o ângulo em duas partes iguais) de um triângulo equilátero (todos os lados são congruentes). O aluno precisa saber que a bissetriz de qualquer ângulo do referido triângulo é a mediana que divide o lado oposto em duas partes iguais e, portanto, que o ângulo formado entre a bissetriz e esse lado só pode ser de $90^{\circ}$, caso contrário, o conceito de reta perpendicular não se dará por completo.

\subsection{Quarta atividade: generalização do pensamento geométrico}

As transformações geométricas possibilitam a generalização do pensamento geométrico, que relaciona os conceitos científicos por meio de axiomas, definições, teoremas. A esse respeito, Volodarskaya (2001, p. 195, tradução nossa) traz importantes contribuições da utilização da teoria de Galperin ao tomar como objeto de investigação "[...] a formação das habilidades generalizadas sobre a execução das transformações geométricas elementares [...] rotação ao redor de um ponto; simetria central e axial; translação paralela e, em geral, as transformações de semelhança e homotetia)."

Os resultados de suas investigações possibitaram a Volodarkaya (2001) afirmar que as transformações geométricas, seja nas rotações, translações, reflexões em torno de um ponto ou eixo central, são formas de do aluno 
generalizar pensamento geométrico ao realizar as transformações da figura no pensamento e materializá-las no desenho (Figura 8).

Figura 8 - Representação da rotação de $180^{\circ}$ de um triângulo em torno do ponto $\mathrm{O}$.

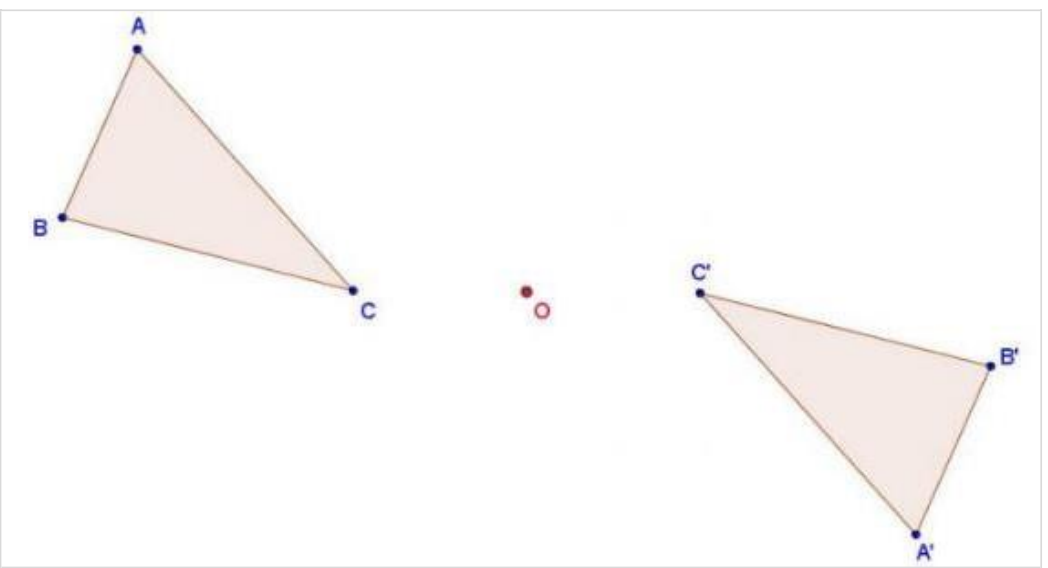

Fonte: Arquivo dos autores (2017).

Em relação às transformações de semelhança e homotetia, é preciso conhecer o significado de constante de proporcionalidade, neste contexto, designada de $K$. O seu significado depende do tipo de conservação da figura após as transformações feitas: no primeiro caso - semelhança, não existe alteração das medidas de seus lados, então $K=1$; no segundo caso - homotetia, existe a alteração das medidas durante o processo de transformação da figura do objeto em outro, então $K \neq 1$ (Figura 9).

Figura 9 - Representação de uma homotetia de $K \neq 1$.

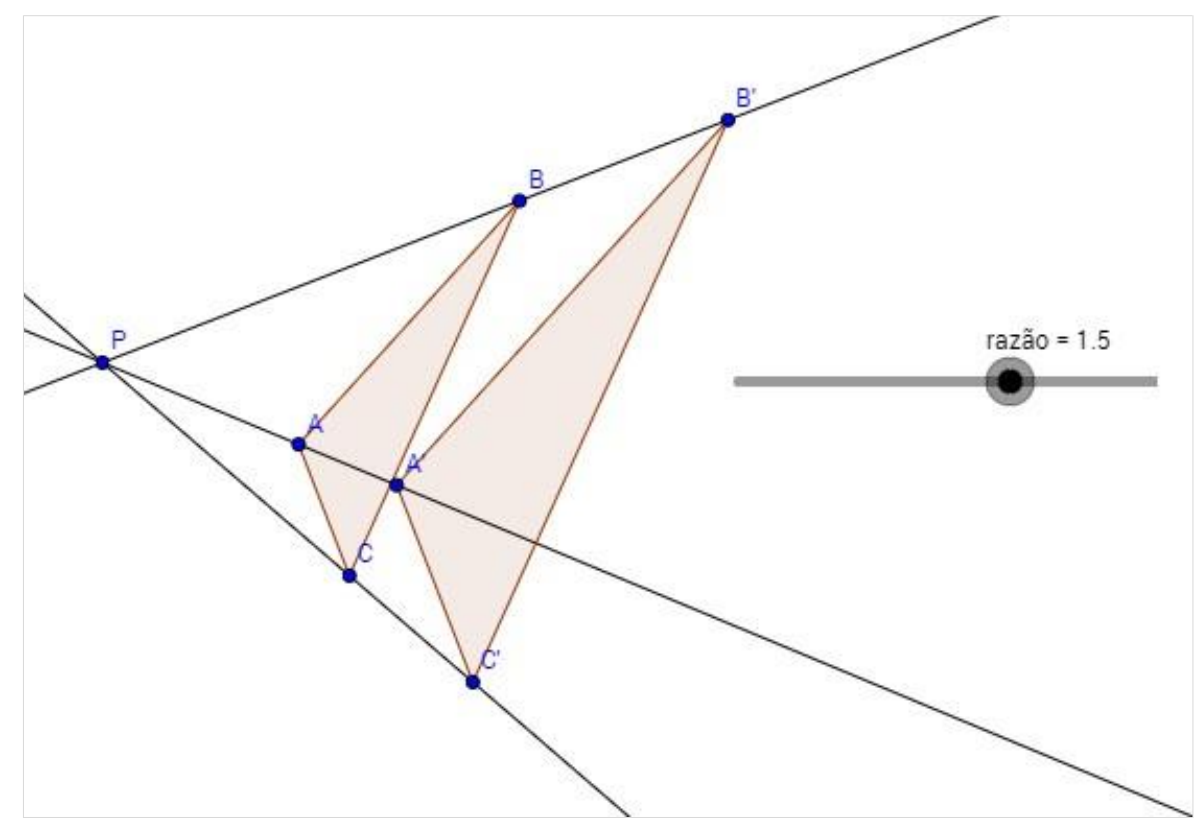

Fonte: Arquivo dos autores (2017). 
Estas transformações, que, inclusive, encontram-se como conteúdos escolares defendidos na Base Nacional Curricular Comum (BNCC), são importantes no ensino da Geometria, haja vista a sua potencialidade de formação da generalização durante as transformações do objeto mediante as ações mentais. Segundo Volodarskaya (2001):

A organização da formação generalizada exigiu dos alunos a assimilação do sistema de conceitos e ações, os quais eles não haviam estudado anteriormente: o conceito acerca da figura orientada, o conceito de vetor, ângulo dirigido, suas igualdades e as regras de sua construção; o conceito de distância entre figuras, o conceito de coeficiente de congruência (homotetia) e outros. Todos estes conceitos e ações prévias se formaram antes do estudo das transformações. (VOLODARSKAYA, 2001, p.205, tradução nossa).

Nas representações de rotações de triângulos (Figura 8) e homotetia (Figura 9), estão exemplos de transformações que utilizam a generalização dos conceitos; em ambas, existe a necessidade de apropriação de muitos outros conceitos, formando o que se poderia considerar um sistema relacional de conceitos. Pode-se afirmar que a generalização dos conceitos se forma e se verifica através de dois momentos; no primeiro, estabelece-se a possibilidade de atividades que utilizam conceitos e ações formadas em novas condições, que se diferenciam uma de outra medida, de condições de ensinar. No segundo, estabelece-se a influência dos conceitos formados sobre o processo de assimilação de conceitos novos, tanto de áreas de conhecimentos, como de áreas diferentes.

\section{Conclusões}

O maior desafio que se coloca às instâncias educativas, e não o único, é efetivar, no ensino-aprendizagem, o aprender, o apropriar das formas mais elaboradas dos conhecimentos historicamente construídos. Considerando que a essência dos conceitos geométricos esteja na experiência social produzida e compartilhada por gerações, a sua apropriação possibilita a formação humana, propriamente dita. Nesta direção, a assimilação dos conceitos encarnados nos conteúdos escolares é condição da aprendizagem escolar e, ao mesmo tempo, meio 
de o ensino promover o desenvolvimento intelectual, afetivo, emotivo, ético dos alunos.

Demonstrou-se, neste texto, as potencialidades formativas e didáticas da teoria de Galperin e do sistema didático de Galperin-Talizina, uma vez que viabilizam um tipo de ensino organizado intencionalmente para o planejamento de ações a serem realizadas pelos estudantes que lhes permitam compreender o processo de assimilação de conceitos geométricos e consequentemente, se apropriarem de um modo de pensar geometricamente. Mostrou-se que o domínio teórico dos conceitos básicos de Geometria, em suas relações lógicas, é condição exigida para a formação de conceitos mais complexos, sendo fundamental quando se almeja o desenvolvimento de habilidades de transformações mentais dos objetos estudados.

O ensino de conteúdos geométricos organizado com o objetivo norteado para a formação do pensamento oportuniza reflexões sobre os sentidos atribuídos pelos alunos a esses conceitos, estabelecendo relações, analisando, argumentando e criando. Há de se destacar o papel do professor e os conhecimentos necessários à sua atuação e, principalmente, que o ensino de Geometria pode ir além das aplicações imediatas do cotidiano ou das abstrações desprovidas de objetividade.

\section{Referências}

BALESTRI, Rodrigo. Matemática: interação e tecnologia, Volume 3. 2. ed. São Paulo: Leya, 2016.

BRASIL. Ministério da Educação. Base Nacional Comum Curricular. Proposta final. Terceira versão. Brasília: MEC, 2017. Disponível em:

$<$ http://basenacionalcomum.mec.gov. br/images/BNCCpublicacao.pdf $>$. Acesso em: ago. de 2017.

FRANCO, Patrícia L. J. O desenvolvimento de motivos formadores de sentido no contexto das atividades de ensino e estudo na escola pública brasileira. 2015, 363f. Tese. (Doutorado em Educação) Programa de Pós-Graduação em Educação. Universidade Federal de Uberlândia, MG. 2015. Disponível em <https:// repositorio.ufu.br/bitstream/123456789/13690/1/DesenvolvimentoMotivosFormad ores.pdf>. Acesso em: out. 2017.

FRANCO, P.L.J; LONGAREZI, A.M.; MARCO, F.F. Organização do ensino de matemática na perspectiva histórico-cultural: um processo didático-formativo. 
Revista Zetetiké - fe/unicamp \& feuff - v. 24, n. 45 - jan/abr-2016. Acesso em: 27 out. 2017.

FRANCO, P.L.J.; LONGAREZI, A.M.; MARCO, F.F. Motives in Brazilian school education according to the cultural historical perspective and the developmental education approach In: Научный результат. Педагогика и психология образования (Resultados Científicos: Pedagogia e Psicologia da Educação). Russia: Universidade Nacional de Pesquisa Estatal de Belgorod, v. 3, n. 3, 2017, p. 51-57. Disponível em: <http://researchresult.ru/media/pedagogy/2017/3/\%D0\%9F\%D0\%B5\%D0\%B4\%D0\%B0\%D0\%B3\% D0\%BE\%D0\%B3\%D0\%B8\%D0\%BA\%D0\%B0_\%D0\%B8_\%D0\%BF\%D1\%81\%D0\% B8\%D1\%85\%D0\%BE\%D0\%BB\%D0\%BE\%D0\%B3\%D0\%B8\%D1\%8F.pdf>. Acesso em: 13 out. 2017.

GALPERIN, P. Ya. Sobre la formación de las imágenes sensoriales y de los conceptos. In: QUINTANAR R, Luís (Org). La formación de las funciones psicológicas durante el desarrollo del niño. Universidad Autónoma de Tlaxcala: Departamento de Educación Especializada, México. Prim. Reimp. 2001.

A formação dos conceitos e as ações mentais. Trad. Caio Morais e Jamile Chastinet. Puentes. In: LONGAREZI, A.M., PUENTES, R.V (orgs). Ensino desenvolvimental: antologia: livro 1. Tradutores Ademir Damázio [etal.]. Uberlândia. MG: EDUFU, 2017. p.199-210.

LEONTIEV, Alexis. N. O desenvolvimento do psiquismo. Lisboa: Horizonte, 1978. Actividad, conciencia e personalidad. Havana: Editorial Pueblo y Educación. 1983.

LOCATELLI, S.C. O ensino de geometria: o que revelam as tarefas escolares? 2015. Dissertação. (Mestrado em Educação). Programa de Pós-graduação em Educação. Universidade Estadual de Maringá. Disponível em: < http://www.ppe.uem.br/dissertacoes/2015\%20-\%20Sueli.pdf>. Acesso em: out. 2017.

LONGAREZI, A.M; FRANCO, P.L.J. A.H. Леонтьев: жизнь и деятельность психолога. Dubna Psychological Journal. Dubna/Russia, 2015, p. 9-44. Disponível em: <http://psyanima.ru/issues/issues-2015/1-2015/> . Acesso em: 22 mar. 2017.

LONGAREZI, A. M; FRANCO, P. L. J. Atividade pedagógica na unidade significado social-sentido pessoal. In: LONGAREZI, A. M.; PUENTES, R. V. Fundamentos Psicológicos e Didáticos do Ensino Desenvolvimental.2017. Coleção Bilbioteca Psicopedagógica e Didática. Série Ensino Desenvolvimental- Edufu. Vol. 5, p. 265-292, 2017. 
MARX, Karl; ENGELS, Friedrich. A ideologia Alemã. Trad. Luis Cláudio de Castro e Costa. São Paulo: Martins Fontes, 2008.

PAVANELLO, Regina Maria. O abandono do ensino da Geometria no Brasil: causas e consequências. Zetetiké, Campinas, ano 1,n. 1, p. 7-17, set. 1993.

PUENTES, R.V. Didática desenvolvimental da atividade: o sistema ElkoninDavidov (1958-2015). Obutchénie. Revista de Didática e Psicologia Pedagógica. Uberlândia, MG. v.1, n.1, p.20-58. 2017. Disponível em: $<$ http://www.seer.ufu.br/index.php/Obutchenie/article/view/38113/20849>. Acesso em: ago. 2017.

RODRIGUES, Adriana. A produção científica sobre Didática na região CentroOeste: um estado da arte a partir de três programas de Pós-Graduação (20042010). 2015, 301f. Tese. (Doutorado em Educação) Programa de Pós-Graduação em Educação. Universidade Federal.

VOLODARSKAYA, I.A. La formación de las habilidades generalizadas del pensamiento geométrico. In: Talízina, N,F. (Compiladora). La formación de las habilidades del pensamiento matemático. San Luis de Potosí, México: Universidad Autónoma de San Luis de Potosí, 2001, p.195-245.

Recebido em novembro de 2017. Aprovado em abril de 2018. 